\title{
The Fate of Old Memories after Medial Temporal Lobe Damage
}

\author{
Peter J. Bayley, ${ }^{1}$ Ramona 0. Hopkins, ${ }^{4,5}$ and Larry R. Squire ${ }^{1,2,3,6}$ \\ Departments of ${ }^{1}$ Psychiatry, ${ }^{2}$ Neurosciences, and ${ }^{3}$ Psychology, University of California, San Diego, California 92093, ${ }^{4}$ Psychology Department and \\ Neuroscience Research Center, Brigham Young University, Provo, Utah 84602, ${ }^{5}$ Department of Medicine, Pulmonary and Critical Care Division LDS \\ Hospital, Salt Lake City, Utah 84143, and ${ }^{6}$ Veterans Affairs Healthcare System, San Diego, California 92161
}

Damage to the hippocampal region and related medial temporal lobe structures (perirhinal, entorhinal, and parahippocampal cortices) impairs new learning (anterograde amnesia) as well as memory for information that was acquired before the damage occurred (retrograde amnesia). We assessed retrograde amnesia with the Autobiographical Memory Interview (AMI) and with a news events test in six patients with damage limited primarily to the hippocampal region ( $\mathrm{H}$ group) and two patients with large medial temporal lobe lesions (MTL group). On the news event test, the H group exhibited temporally limited retrograde amnesia covering $\sim 5$ years. On the same test, the MTL group exhibited an extensive retrograde amnesia covering decades. Nevertheless, performance was relatively spared for very remote time periods. On the AMI, all patients had intact remote autobiographical memory. Because our patients with hippocampal lesions, as well as our patients with large MTL lesions, performed normally on the AMI, patients who perform poorly on the same test presumably have damage beyond the hippocampus and related structures in the medial temporal lobe. The findings emphasize the difference in the extent of retrograde amnesia associated with hippocampal lesions and large MTL lesions.

Key words: amnesia; consolidation; hippocampus; learning; memory; retrograde

\section{Introduction}

Damage to the hippocampal region (the CA fields, the dentate gyrus, and the subicular complex) and related medial temporal lobe structures (perirhinal, entorhinal, and parahippocampal cortices) impairs new learning (anterograde amnesia) as well as memory for information that was acquired before the damage occurred (retrograde amnesia). Early descriptions of retrograde amnesia led to the principle that recently acquired memories are more impaired than remote memories (Ribot, 1881), and a large literature involving both humans and experimental animals has supported this idea (Squire and Alvarez, 1995; Frankland and Bontempi, 2005). Nevertheless, questions remain about two aspects of retrograde amnesia. First, can damage limited to the medial temporal lobe sometimes cause extensive, ungraded memory loss rather than temporally graded retrograde amnesia? Second, after medial temporal lobe damage, what is the status of memory for remote autobiographical events?

With respect to the first question, some investigators concluded that retrograde amnesia is temporally ungraded and that recent and remote memories are similarly impaired (Sanders and Warrington, 1971; Warrington, 1996). By this view, retrograde amnesia can be lifelong, even when damage is reported to be limited to the hippocampus itself (Cipolotti et al., 2001). Other investigators concluded that retrograde amnesia is temporally

\footnotetext{
Received Sept. 29, 2006; revised Nov. 3, 2006; accepted Nov. 15, 2006.

This work was supported by the Medical Research Service of the Department of Veterans Affairs, National Institute of Mental Health Grant 24600, and the Metropolitan Life Foundation. We thank Jennifer Frascino, Mark Starr, and Christine Smith for assistance.

Correspondence should be addressed to Dr. Larry R. Squire, Veterans Affairs Medical Center 116A, 3550 La Jolla Village Drive, San Diego, CA 92161. E-mail: Isquire@ucsd.edu.

D0I:10.1523/JNEUROSCI.4262-06.2006

Copyright $\odot 2006$ Society for Neuroscience $\quad 0270-6474 / 06 / 2613311-07 \$ 15.00 / 0$
}

limited and related to the extent and locus of damage (Eichenbaum et al., 1999; Squire et al., 2004b). Thus, when damage is restricted to the hippocampal region, retrograde amnesia can be limited to several years (Reed and Squire, 1998; Manns et al., 2003), but after much larger medial temporal lobe lesions, retrograde amnesia is temporally extended (Reed and Squire, 1998).

It is noteworthy that in the early study of five patients by Sanders and Warrington (1971), the conclusion that retrograde amnesia was extensive and ungraded was based on tests of news events and famous faces that covered up to 38 years before the onset of amnesia (mean, 32 years). On average, the patients were 20-24 years old at the time that the most remote events in the news events test occurred and $\sim 35$ years old at the time covered by the most remote items on the faces test. Another patient was 34-38 years old at the time covered by the most remote test items (Cipolotti et al., 2001). To determine whether patients have ungraded retrograde amnesia that extends into their early life, it would be necessary to assess factual knowledge from earlier time periods.

With respect to autobiographical memory, it has been proposed that medial temporal lobe damage, or even limited hippocampal damage, leads to a prolonged retrograde amnesia (Hirano and Noguchi, 1998; Cipolotti et al., 2001; Steinvorth et al., 2005; Moscovitch et al., 2006). In other studies, both patients with limited hippocampal lesions, as well as patients with large medial temporal lobe lesions, had intact autobiographical memory from early life (Rempel-Clower et al., 1996; Bayley et al., 2003, 2005b).

Studies of autobiographical memory present a number of challenges. One difficulty is that a relatively small number of patients have been studied, and anatomical information about the patients is often limited. In a recent commentary, only two 
patients (N.T. and V.C.) were presented to make a case that hippocampal damage is sufficient to impair remote autobiographical memory (Cipolotti and Moscovitch, 2005; for critical comments, see Squire and Bayley, 2006). Three other patients have also been reported to have impaired remote autobiographical memory caused by medial temporal lobe damage (Hirano and Noguchi, 1998; Steinvorth et al., 2005). Our finding of intact remote autobiographical memory was based on six patients for whom detailed anatomical information was available (Bayley et al., 2003) and a second study of five of the same patients (Bayley et al., 2005b). A further difficulty is that the most comprehensive methods for assessing autobiographical memory involve scoring tape-recorded narratives, for example, determining the number of details produced about events from early life. Yet these methods are inevitably subjective, and it is difficult to compare results across laboratories. A more satisfying approach would be to use an instrument that is easy to administer in different settings.

We have tested eight patients, seven of whom had undergone whole-brain volumetric analysis. The patients were divided into two groups based on the locus and extent of their lesions: six patients have lesions thought to be restricted to the hippocampus (plus dentate gyrus and subicular complex), and two patients have large medial temporal lobe lesions. Retrograde amnesia for fact memory was assessed using a news events test that covered early adulthood and adolescence. Retrograde amnesia for autobiographical memory was assessed using the Autobiographical Memory Interview (AMI) (Kopelman et al., 1989). This is a simple, standardized test that assesses two aspects of autobiographical memory: personal semantic memory and memory for specific autobiographical incidents. In each case, the test covers three time periods: the recent past (i.e., the past year), early adult life, and childhood. The AMI has been used in other studies and thereby allows comparisons to be made among patients studied in different laboratories.

\section{Materials and Methods}

Participants

Eight amnesic patients participated (seven males) (Table 1). Of these, six patients (H group: A.B., K.E., L.J., R.S., G.W., J.R.W.) have bilateral lesions thought to be limited to the hippocampal region (CA fields, dentate gyrus, and subicular complex). Two patients (MTL group: E.P., G.P.) have damage to the hippocampal region as well as adjacent medial temporal lobe cortex.

Although all the patients exhibited significant memory impairment, it is clear from informal observation and from test scores that the two patients in the MTL group are more severely amnesic than the patients in the H group. For example, on a standard test of recognition memory [Rey Auditory Learning Test (Rey, 1964)], patients A.B., K.E., L.J., R.S., G.W., and J.R.W. scored 83, 88, 93, 87.3, 88, and 89.3\% correct, respectively, across five study test trials involving 15 target words (mean \pm SEM $=$ $88.1 \pm 1.3 \%$ correct), whereas patients E.P. and G.P. scored 65 and 54\%, respectively $($ mean $=59.5 \pm 5.5 \%$ correct $)\left(t_{(6)}=8.1 ; p<0.001\right)$. Nonetheless, the recognition memory scores of both patient groups were impaired relative to controls $[n=8$ from a study by Shimamura and Squire (1986); mean $=97.6 \pm 0.38 \%$ correct; all $p$ values $<0.05]$. Furthermore, unlike the patients in the $\mathrm{H}$ group who have demonstrated substantial new fact learning since they became amnesic (Manns et al., 2003), the two patients in the MTL group have demonstrated little fact learning (Bayley and Squire, 2005). Indeed, during repeated testing over many weeks, they do not recognize that they have been tested before (Bayley et al., 2005a).

A.B. became amnesic in 1976 after an anoxic episode associated with cardiac arrest. K.E. became amnesic in 2004 after an episode of ischemia associated with kidney failure and toxic shock syndrome. L.J. became amnesic in 1988 during a 6 month period with no known precipitating event. Her memory impairment has been stable since that time. Patients R.S. and G.W. became amnesic in 1998 and 2001, respectively, after a drug overdose and associated respiratory failure. Patient J.R.W. became amnesic in 1990 after an anoxic episode associated with cardiac arrest. Patients E.P. and G.P. became amnesic in 1992 and 1987, respectively, after contracting viral encephalitis.

For seven of the eight patients, estimates of medial temporal lobe damage were based on quantitative analysis of magnetic resonance images compared with data for 19 controls (for K.E., R.S., G.W., J.R.W., E.P. and G.P.), or 11 controls (L.J.). Nine coronal magnetic resonance images from six of these seven patients (all but J.R.W) are available at www. jneurosci.org as supplemental material to Shrager et al. (2006) and for five of the patients (all but E.P. and G.P.) at www.neuron.org as supplemental material to Wais et al. (2006). The volume of the full anteriorposterior length of the hippocampus and the parahippocampal gyrus were measured following published procedures (Amaral and Insausti, 1990; Insausti et al., 1998). For each patient, the hippocampal and parahippocampal gyrus volumes were divided by the intracranial volume to correct for brain size (Gold and Squire, 2005). In the H group, K.E., L.J., R.S., G.W., and J.R.W. have an average bilateral reduction in hippocampal volume of $49,46,33,48$, and $44 \%$, respectively (all values $>3$ SDs below the control mean). On the basis of two patients (L.M. and W.H.) with similar bilateral volume loss in the hippocampus for whom detailed postmortem neurohistological information was obtained (RempelClower et al., 1996), this degree of volume loss likely reflects nearly complete loss of hippocampal neurons (Gold and Squire, 2005). In comparison, the volume of the parahippocampal gyrus is reduced by $17,-8,1$, 12 , and $6 \%$, respectively (all values within 2 SDs of the control mean).

A.B. is unable to participate in magnetic resonance imaging (MRI) studies but is thought to have hippocampal damage on the basis of etiology (anoxia) and a neurological examination indicating well circumscribed amnesia. In addition, high-resolution computed tomography images obtained in 2001 were consistent with damage restricted to the hippocampal region (Schmolck et al., 2002). In the MTL group, patients E.P. and G.P. have an average bilateral reduction in hippocampal volume of 97 and $96 \%$, respectively (all values $>9$ SDs below the control mean). In addition, the volume of the parahippocampal gyrus was reduced by 94 and $93 \%$, respectively (all values $>10$ SDs below the control mean).

Additional measurements, based on four controls for each patient, were made for the frontal lobes, lateral temporal lobes, parietal lobes, occipital lobes, insular cortex, and fusiform gyrus (Bayley et al., 2005b). In the $\mathrm{H}$ group, the only volume reduction in these regions $>1.3 \mathrm{SDs}$ of the control mean was the parietal lobe of R.S. (Bayley et al., 2005b). This finding for patient R.S. likely reflects natural variation in the parietal lobe volume rather than damage to this brain region because the parietal lobes are highly variable in size (Raz et al., 2005). In addition, no evidence of parietal lobe damage is apparent in R.S.'s MRI scan. He also obtained a 
normal score on the block design test [scaled score, 11; Wechsler Adult Intelligence Scale-Revised (Wechsler, 1981)], which is known to be sensitive to parietal lobe damage (Lezak, 1995). For E.P. and G.P., the volumes of each of the major lobes are all within 9 and 13\% of control volumes, respectively. E.P.'s lesion also includes the rostral portion of the fusiform gyrus (39\% on the left and $68 \%$ on the right) and the insula, which is reduced in size (32\% on the left and $30 \%$ on the right). G.P.'s lesion includes the fusiform gyrus ( $41 \%$ on the left and $56 \%$ on the right) and the insula ( $80 \%$ on the left and $49 \%$ on the right).

Three groups of controls participated. One group consisted of 13 individuals (nine males), who served as controls for the autobiographical memory interview. These individuals averaged 65.6 years of age and 14.6 years of education (H group: mean age, 51.6 years; mean education, 13.9 years; MTL group: average age, 64.8 years of age at test; average education, 14.0 years). Two additional control groups participated in the news events test. One group ( $n=13 ; 10$ males) was matched to the H group. They averaged 59.8 years of age and 15.0 years of education ( $\mathrm{H}$ group: mean age, 55.7 years; mean education, 13.5 years). The second group ( $n=7$; four males) was matched to patient E.P. They averaged 77.1 years of age and 11.7 years of education.

\section{Memory tests}

Autobiographical Memory Interview. This standardized test (Kopelman et al., 1989) quantifies the recall of autobiographical incidents and personal semantic facts using a structured interview. Participants were asked to provide information from three different time periods: childhood (until 18 years old), early adulthood (19-29 years old), and recent (within the last year). For the autobiographical portion of the test (autobiographical memory), participants were asked to recall three unique events from each of the three time periods (e.g., "Describe an incident that occurred to you while attending high school."). The maximum score was 9 for each time period (maximum three points per item, $0-3$ scoring scale). The portion of the test that assessed personal facts (Personal Semantic Memory) consisted of 41 items (childhood, $n=12$; early adulthood, $n=16$; recent, $n=13$ ). Participants were asked to recall personal semantic knowledge (e.g., "What was your home address while attending high school?"), and the maximum score was 21 for each time period. For each patient, the accuracy of their responses was ascertained by interviewing at least two family members who were familiar with virtually his/her entire lifetime. Responses were assigned a score of zero if the data were found to be inaccurate. Data for five of the patients in the present study have been published previously for parts of this test (Reed and Squire, 1998; Bayley et al., 2003).

News events test. This test was a modified version of a test constructed by Manns et al. (2003). Tests of past public events, like this one, are sufficiently specific that it is difficult to answer the questions correctly unless an individual has lived through the time period in question (Warrington and Silberstein, 1970; Squire, 1974). For the H group, their 13 controls, and patient G.P., the test included 279 questions about news events that had occurred between 1951 and 2005 [e.g., Which state's contested electoral votes were the deciding factors in George W. Bush's controversial win of the presidency? (Florida); What tire manufacturer recalled thousands of tires? (Firestone)]. Because E.P. was older than the other patients in the study, he and his seven controls were given the same 279 questions that the other participants received, plus 21 additional questions covering the period 1938-1950. All testing was in a free-recall format and took place across two to three sessions. The data for each patient and two to three controls matched to each patient for age and education (seven controls for E.P. and G.P.) were analyzed according to the year in which the patient became amnesic. In this way, a score for each patient and each patient's controls was calculated for the period of anterograde amnesia and in 5 year intervals for a period of up to 30 years of retrograde amnesia. For example, for G.W. who became amnesic in 2001, 87 questions assessed his anterograde time period (2001-2005), and 136 questions assessed his retrograde time period (1971-2000). His performance was not recorded for the 56 remaining questions, which would have assessed the time when he was younger than 11 years. For E.P., who became amnesic in 1992, 171 questions assessed his anterograde time period (1992-2005), and 129 questions assessed his retrograde time pe-

\section{Personal Semantic Memory}

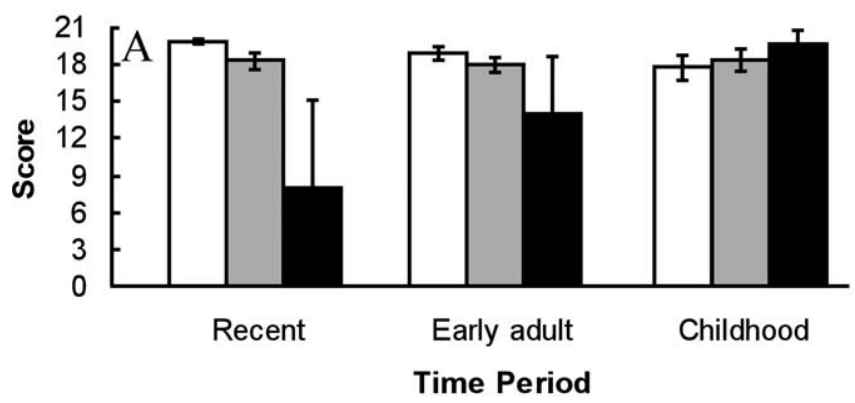

$\mathrm{CON}(\mathrm{n}=13)$
$\square(\mathrm{n}=6)$
$\operatorname{MTL}(\mathrm{n}=2)$

\section{Autobiographical Memory}

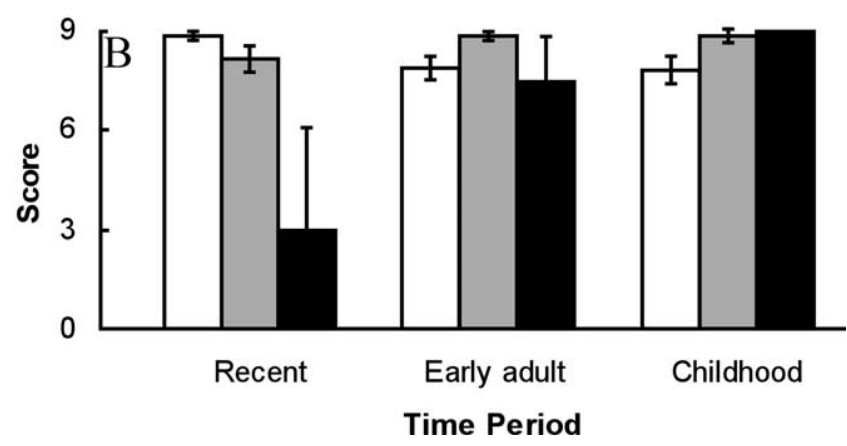

Figure 1. Performance on the Autobiographical Memory Interview. $A$, Scores on items that assessed factual knowledge about a person's own past (maximum score, 21). $\boldsymbol{B}$, Scores on items that assessed memory for autobiographical events (maximum score, 9). Error bars indicate SEM.

riod (1938-1991). Thus, his memory was sampled back to the time 51-55 years before the onset of his amnesia when he was 15-19 years old. Across participants, an average of 35 questions was used for each of the time intervals sampled (minimum, 8.0 questions at the -25 to -30 year interval).

\section{Results}

\section{Autobiographical Memory Interview}

The H group exhibited mild memory impairment limited to the recent time period (Fig. 1), which reached significance in the case of autobiographical events $(p=0.05)$. Memory was intact for personal facts and for autobiographical events from early adulthood and childhood. The MTL group was markedly impaired at recollecting both personal facts and autobiographical events from the recent time period ( $p$ values $=0.02$ ). Performance was numerically low, albeit not significantly so, in the early adult time period and fully intact for childhood (all $p$ values $>0.05$ ).

\section{News events test}

Figure 2 shows the performance of six patients with damage to the hippocampal region $(\mathrm{H})$ and 13 controls (CONs) on questions about news events (1951-2005). For the period of anterograde amnesia, the $\mathrm{H}$ group performed more poorly than controls (patients, $32.7 \pm 2.5 \%$ correct; controls, $61.5 \pm 4.2 \%$ correct; $\left.t_{(17)}=4.46 ; p<0.001\right)$. Thus, since the onset of their amnesia, these patients have not acquired as much information 


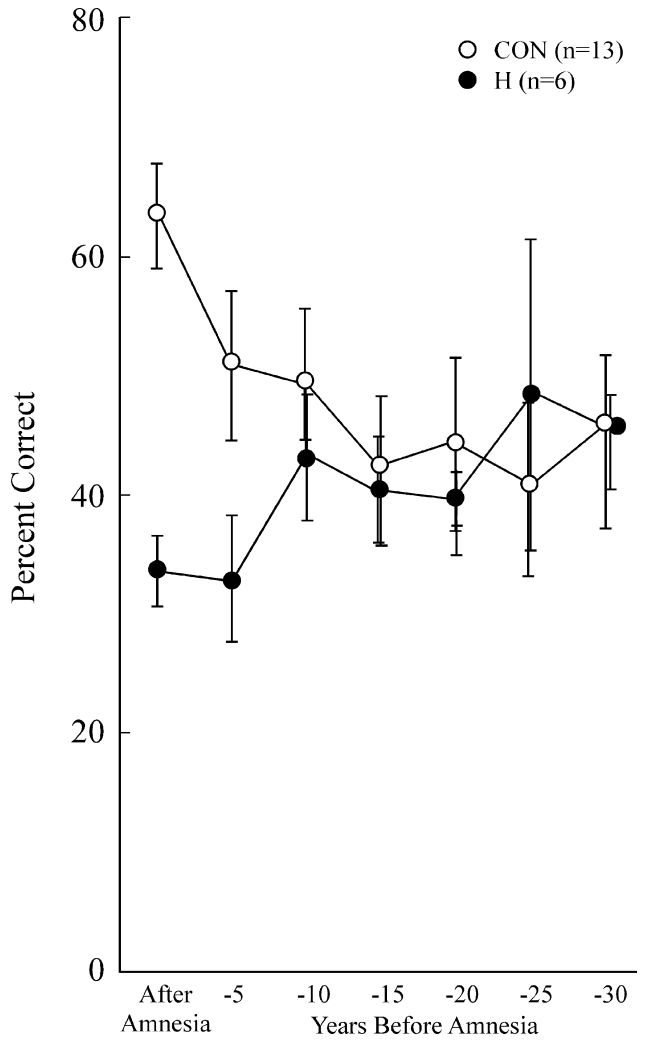

Figure 2. Recall performance on a test of news events that occurred from 1951 to 2005. The scores for six patients with damage limited primarily to the hippocampal region and 13 controls have been aligned relative to the onset of amnesia (see Materials and Methods) so that performance can be shown for the time period after the onset of amnesia and for 5 year intervals preceding the onset of amnesia (retrograde amnesia). The data point at -5 represents 1-5 years before amnesia, the point at -10 represents $6-10$ years before amnesia, and so on. Error bars indicate SEM.

about news events as their healthy counterparts. In addition, the $\mathrm{H}$ group exhibited temporally limited retrograde amnesia covering a period of $\sim 5$ years before the onset of amnesia. For the time period 1-5 years before amnesia, the patients were marginally impaired relative to controls (patients, $32.1 \pm 5.0 \%$ correct; controls, $50.2 \pm 5.7 \%$ correct; $\left.t_{(17)}=1.97 ; p=0.066\right)$. In addition, the patients performed even better for the 6-10 years before amnesia than for the 5 years immediately preceding amnesia ( $41.6 \mathrm{vs}$ $32.1 \%$ correct; $t_{(5)}=3.67 ; p<0.02$ ). Further, an ANOVA comparing patients and controls for the $1-5$ years and 6-10 years preceding amnesia revealed an interaction of group by time period $\left(F_{(1,17)}=4.7 ; p<0.05\right)$. For more remote time periods (11-30 years before amnesia), performance of the patients and controls was virtually identical (patients, $42.6 \%$ correct; controls, $41.6 \%$ correct).

Figure 3 shows the performance of the two patients with large medial temporal lobe lesions (E.P. and G.P.) and seven controls on questions about news events (1938-2005). The patients performed very poorly in their period of anterograde amnesia (E.P., $3.8 \%$ correct; G.P., $4.0 \%$ correct; controls, $38.5 \pm 4.6 \%$ correct). In addition, both E.P. and G.P. exhibited extensive retrograde amnesia covering many years before the onset of their amnesia. Nevertheless, both patients improved their scores as the questions covered more remote time periods. G.P.'s scores improved when the questions covered the period $>20$ years before the onset of amnesia. Specifically, whereas G.P.'s scores were $>2$ SDs below the control scores for three of the four most recent time periods,

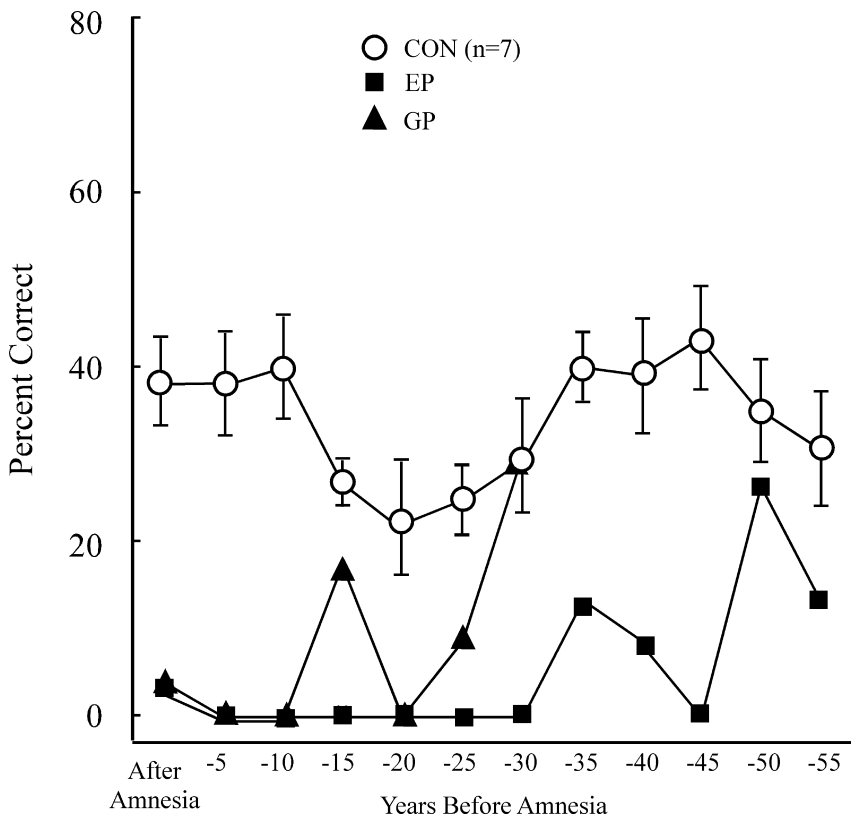

Figure 3. Recall performance on a test of news events that occurred from 1938 to 2005 (E.P.) and from 1951 to 2005 (G.P.). The scores for the two patients with large medial temporal lobe lesions and seven controls have been aligned relative to the onset of amnesia (see Materials and Methods) so that performance can be shown for the time period after the onset of amnesia and for 5 year intervals preceding the onset of amnesia (retrograde amnesia). The data point at -5 represents $1-5$ years before amnesia, the point at -10 represents $6-10$ years before amnesia, and so on. Error bars indicate SEM.

he scored within 1.1 SDs of controls at the -21 to -25 year time period and he scored as well as controls at the -26 to -30 year period when he would have been $12-16$ years old. E.P. exhibited extensive retrograde amnesia covering 30-50 years. Nevertheless, his performance improved when the questions concerned events that had occurred $>30$ years before his amnesia, and he reached normal levels for the period 46-50 years before amnesia when he was 20-24 years old. Specifically, E.P. scored consistently $>2$ SDs below the control scores except at three of the four most remote time periods $(-40,-50$, and -55 years; $-1.7,-0.5,-1.1$ SDs, respectively). There were also two earlier time points $(-20$ and -30 years) when E.P. scored zero but where (because of variability in the control scores) he scored only 1.6 SDs below the controls.

We note that the older controls (mean age, 77.1 years) who were matched to E.P. and G.P. performed worse on the news events test than the younger controls (mean age, 59.8 years) who were matched to the patients with hippocampal lesions (overall performance for the period 1951-2005, 31.6 $\pm 2.9 \%$ vs $45.7 \pm$ $\left.4.2 \% ; t_{(18)}=2.30 ; p<0.04\right)$. The finding that older adults typically perform less well than younger adults on tests about news events has been well documented (Warrington and Silberstein, 1970; Squire, 1974).

\section{Discussion}

The effects of medial temporal lobe damage on autobiographical memory and memory for news events were examined in two groups of patients. Six patients had damage limited primarily to the hippocampal region (H group), and two patients had extensive damage to the medial temporal lobe that included perirhinal and entorhinal cortices, and much of the parahippocampal cortex (MTL group). There were two main findings. First, retrograde amnesia can be either temporally limited or quite extended, de- 
pending on the amount of damage (hippocampus vs hippocampus plus adjacent medial temporal cortex). As measured by the news events test, the $\mathrm{H}$ group had a retrograde amnesia of $\sim 5$ years. On the same test, the MTL group exhibited a retrograde amnesia that extended 20-30 (G.P.) or 30-50 (E.P.) years. Yet, even when retrograde amnesia was extensive, memory for very remote time periods was relatively spared. The second main finding was that all the patients had intact remote autobiographical memory from their childhood and adolescence.

We suggest that some patients who have been described as having ungraded and extensive retrograde amnesia might have exhibited a temporal gradient if earlier time periods had been tested. For example, patient N.T. was initially reported to have an ungraded retrograde memory impairment for factual knowledge (Sanders and Warrington, 1971). Yet, the test of news events that she was given extended to only 30 years before the onset of her amnesia when she was 23 years old. The test of famous faces extended to only 15 years before the onset of her amnesia when she was 37 years old. Similarly, patient V.C. exhibited an extended and ungraded retrograde amnesia for news events and famous faces, but the tests did not cover time periods when he was younger than 34 years (Cipolotti et al., 2001). It would be interesting to assess his retrograde amnesia with tests that include items from early adulthood or adolescence.

Our conclusion that severely amnesic patients can recall information about very remote news events is limited to patients who have bilateral damage restricted mainly to the medial temporal lobe. Other memory-impaired patients have been described who have more extensive damage that includes lateral temporal cortex (Damasio et al., 1985; Reed and Squire, 1998; Kapur, 1999). These patients all had extended, ungraded retrograde amnesia covering a number of years, and it is possible that their remote memory performance would be poor even on tests that cover very early time periods. Note that E.P. and G.P. both have some volume reduction in the fusiform gyrus and insular cortex. Accordingly, one cannot exclude the possibility that damage in these regions contributed to the severity and extent of their retrograde amnesia. Nonetheless, it is of interest that, despite their large lesions, both patients exhibited good memory for the most remote time periods.

The relatively short temporal gradient of retrograde amnesia in patients with hippocampal lesions is consistent with the view that the human hippocampus has a time-limited role in the formation and storage of semantic knowledge. By this view, memories are initially dependent on the hippocampus as well as on distributed regions of neocortex. Through a gradual process of consolidation and reorganization, connections among the cortical regions are progressively strengthened until the cortical memory is independent of the hippocampus (McClelland et al., 1995; Squire and Alvarez, 1995). Temporally limited retrograde amnesia has also been frequently observed in experimental animals with a time scale ranging from weeks to months (Squire et al., 2004a; Frankland and Bontempi, 2005). In the case of large medial temporal lobe lesions that damage the perirhinal, entorhinal, and parahippocampal cortices in addition to the hippocampus, as in patients E.P. and G.P., the retrograde amnesia covers several decades. These cortices must have a role in memory storage that extends well beyond the temporary role of the hippocampus itself. The concept of consolidation, as it applies to hippocampal function, does not easily apply to the adjacent cortex.

The findings for autobiographical memory were similar to the findings for factual knowledge. Remote autobiographical memory was intact in all the patients that we studied. Indeed, seven of the eight patients obtained the maximum score of nine points on the childhood portion of the autobiographical incidents schedule of the AMI (L.J. scored 8 points). Similar findings with the AMI were reported for patients M.R. and P.D. (Eslinger, 1998) and for patient B.E. (Kapur and Brooks, 1999), all of whom had bilateral damage thought to be limited to the medial temporal lobe. In contrast, other memory-impaired patients have been reported (usually in single-case studies) to do poorly on the childhood portion of the AMI [patient Y.K., 4/9 points (Hirano and Noguchi, 1998); patient V.C., 1/9 points (Cipolotti et al., 2001); patient T.T., 0/9 (Maguire et al., 2006); patient K.C., 2/9 (Rosenbaum et al., 2004); patient R.S., 0/9 (Kitchener et al., 1998); patient E.K., 4/9 (Eslinger, 1998)]. It has been proposed that the autobiographical narratives of patients with medial temporal lobe lesions lack the richness of detail that appears in the narratives of controls and that this deficiency can be detected only by using sensitive tests (Nadel et al., 2000). Others have suggested that unless comparable techniques are used across laboratories, differences in findings might be caused by how autobiographical memory is assessed (Rosenbaum et al., 2004). The present study addresses these points. We used a simple standardized test and found very remote memory to be intact. The different results recorded in the literature cannot be attributed to differences in test procedures, subjective testing methods, or obscure scoring techniques.

The likely explanation for why some patients perform well on the AMI and others do not is that there are differences in the locus and extent of the lesions. Our results show that even patients with extensive damage to the medial temporal lobe (E.P. and G.P.) can obtain maximum scores on the childhood portion of the test. This result suggests that those patients who do poorly on the same test, including Y.K., V.C., T.T., K.C., R.S., and E.K., as cited above, must have some damage beyond what is present in patients E.P. and G.P. Indeed, additional damage has been identified in most of these cases. Patient K.C. has significant damage in frontal, parietal, and occipital cortices (Rosenbaum et al., 2005), patient V.C. has evidence of hypometabolism in the right thalamus and in right parietal cortex (Kapur et al., 1999), patient R.S. has damage to the basal forebrain and medial frontal lobe (Kitchener et al., 1998), T.T. has evidence of abnormality in the anterior temporal lobes [case 8 (Vincent et al., 2004)], and patient E.K. has bilateral lesions involving lateral temporal cortex (Eslinger, 1998). In addition, remote autobiographical memory was substantially impaired in three other patients, who had damage to one or more cortical areas including the lateral temporal and frontal lobes (Bayley et al., 2005b). Others have also emphasized the importance of lateral temporal and frontal lobe pathology for understanding impaired remote autobiographical memory (Eslinger, 1998; Kapur, 1999; Kopelman et al., 1999; Bright et al., 2006). There is a need for thorough, quantitative anatomical information for all the patients being studied.

Data from the AMI about autobiographical incidents have not been reported for two other patients (H.M. and N.T.) who were described as having impaired remote autobiographical memory. The well known patient H.M. sustained a bilateral medial temporal lobe resection at the age of 27 years for the treatment of severe temporal lobe epilepsy that had begun at age 10 (Corkin et al., 1997). H.M. was long considered to have intact remote autobiographical memory from before the age of 17 (Corkin, 1984; Sagar et al., 1985). More recently, however, H.M.'s remote autobiographical memory was reported to be impaired (Steinvorth et al., 2005). H.M. was asked to provide details for a single event from each of five time periods. Although he was unable to recall a memory from early childhood ( $0-11$ years old), for a more recent 
time period (12-17 years old) he produced nearly 100 details and scored above the control mean. The data thus provide a somewhat ambiguous picture. Yet even if H.M. is considered deficient, there is some question whether his deficiency can be attributed to his medial temporal lobe lesion. Extended retrograde amnesia for autobiographical events has been reported in patients with temporal lobe epilepsy who have not had surgery (Kapur, 1997). In addition, recent MRI scans document a number of abnormalities outside H.M.'s medial temporal lobe, including cortical and subcortical atrophy, large amounts of abnormal white matter, and subcortical infarcts (Salat et al., 2006). These findings are thought to have appeared during the last decade, and they complicate the interpretation of H.M.'s autobiographical memory abilities, which were assessed during the same time period.

Patient N.T. had a right temporal lobectomy and was subsequently found postmortem to have left hippocampal damage (Warrington and Duchen, 1992). The large right temporal lobe excision left intact only part of the superior temporal gyrus. It is therefore puzzling that N.T.'s retrograde amnesia has been attributed to selective hippocampal damage (Chan et al., 2002). Further, although N.T. was described as having impaired autobiographical memory from early life, formal assessments were not conducted. The observation was made that N.T. was "very unclear about what she had done in the war years... during the $1939 / 1940$ period" when she was 32-33 years old in London during the Blitz. Nothing is reported about her autobiographical memory from before that time. Thus, it is not known whether N.T.'s memories from her childhood, adolescence, and even early adulthood were intact or impaired.

There are two ways to understand cases where retrograde amnesia for factual knowledge or autobiographical events is described as extensive and ungraded. One possibility is that memory was not fully evaluated and that a more complete description of retrograde amnesia would reveal that very remote memory is intact. The second possibility is that significant damage is present outside the medial temporal lobe (e.g., in lateral temporal cortex), and that the presentation of retrograde amnesia in this circumstance is distinct from, and does not generalize to, what is found after restricted medial temporal lobe lesions. The present findings rule out a third possibility, namely, that damage limited largely to the medial temporal lobe, or the hippocampus itself, causes extensive and ungraded retrograde amnesia for factual knowledge or autobiographical events.

\section{References}

Amaral DG, Insausti R (1990) The human hippocampal formation. In: The human nervous system (Paxinos G, ed), pp 711-755. San Diego: Academic.

Bayley PJ, Squire LR (2005) Failure to acquire new semantic knowledge in patients with large medial temporal lobe lesions. Hippocampus 15:273-280.

Bayley PJ, Hopkins RO, Squire LR (2003) Successful recollection of remote autobiographical memories by amnesic patients with medial temporal lobe lesions. Neuron 37:135-144.

Bayley PJ, Frascino JC, Squire LR (2005a) Robust habit learning in the absence of awareness and independent of the medial temporal lobe. Nature 436:550-553.

Bayley PJ, Gold JJ, Hopkins RO, Squire LR (2005b) The neuroanatomy of remote memory. Neuron 46:799-810.

Bright P, Buckman J, Fradera A, Yoshimasu H, Colchester AC, Kopelman MD (2006) Retrograde amnesia in patients with hippocampal, medial temporal, temporal lobe, or frontal pathology. Learn Mem 13:545-557.

Chan D, Revesz T, Rudge P (2002) Hippocampal, but not parahippocampal, damage in a case of dense retrograde amnesia: a pathological study. Neurosci Lett 329:61-64.
Cipolotti L, Moscovitch M (2005) The hippocampus and remote autobiographical memory. Lancet Neurol 4:792-793.

Cipolotti L, Shallice T, Chan D, Fox N, Scahill R, Harrison G, Stevens J, Rudge P (2001) Long-term retrograde amnesia: the crucial role of the hippocampus. Neuropsychologia 39:151-172.

Corkin S (1984) Lasting consequences of bilateral medial temporal lobectomy: clinical course and experimental findings in H.M. Semin Neurol 4:249-259.

Corkin S, Amaral DG, Gonzalez RG, Johnson KA, Hyman BT (1997) H.M.'s medial temporal lobe lesion: findings from magnetic resonance imaging. J Neurosci 17:3964-3979.

Damasio AR, Eslinger PJ, Damasio H, Van Hoesen GW, Cornell S (1985) Multimodal amnesic syndrome following bilateral temporal and basal forebrain damage. Arch Neurol 42:252-259.

Eichenbaum H, Dudchenko P, Wood E, Shapiro M, Tanila H (1999) The hippocampus, memory, and place cells: is it spatial memory or a memory space? Neuron 23:209-226.

Eslinger P (1998) Autobiographical memory after temporal lobe lesions. Neurocase 4:481-495.

Frankland PW, Bontempi B (2005) The organization of recent and remote memories. Nat Rev Neurosci 6:119-130.

Gold JJ, Squire LR (2005) Quantifying medial temporal lobe damage in memory-impaired patients. Hippocampus 15:79-85.

Hirano M, Noguchi K (1998) Dissociation between specific personal episodes and other aspects of remote memory in a patient with hippocampal amnesia. Percept Mot Skills 87:99-107.

Insausti R, Juottonen K, Soininen H, Insausti AM, Partanen K, Vainio P, Laakso MP, Pitkanen A (1998) MR volumetric analysis of the human entorhinal, perirhinal, and temporopolar cortices. Am J Neuroradiol 19:659-671.

Kapur N (1997) Autobiographical amnesia and temporal lobe pathology. In: Studies in the neuropsychology of memory (Parkin AJ, ed), pp 37-62. Hove, UK: Psychology Press.

Kapur N (1999) Syndromes of retrograde amnesia: a conceptual and empirical synthesis. Psychol Bull 125:800-825.

Kapur N, Brooks DJ (1999) Temporally-specific retrograde amnesia in two cases of discrete bilateral hippocampal pathology. Hippocampus 9:247-254.

Kapur N, Thompson P, Kartsounis LD, Abbott P (1999) Retrograde amnesia: clinical and methodological caveats. Neuropsychologia 37:27-30.

Kitchener EG, Hodges JR, McCarthy R (1998) Acquisition of post-morbid vocabulary and semantic facts in the absence of episodic memory. Brain 121:1313-1327.

Kopelman MD, Wilson BA, Baddeley AD (1989) The autobiographical memory interview: a new assessment of autobiographical and personal semantic memory in amnesic patients. J Clin Exp Neuropsychol 5:724-744.

Kopelman MD, Stanhope N, Kingsley D (1999) Retrograde amnesia in patients with diencephalic, temporal lobe or frontal lesions. Neuropsychologia 37:939-958.

Lezak MD (1995) Neuropsychological assessment, Ed 3. New York: Oxford UP.

Maguire EA, Nannery R, Spiers HJ (2006) Navigation around London by a taxi driver with bilateral hippocampal lesions. Brain 129:2894-2907.

Manns JR, Hopkins RO, Squire LR (2003) Semantic memory and the human hippocampus. Neuron 37:127-133.

McClelland JL, McNaughton BL, O’Reilly RC (1995) Why there are complementary learning systems in the hippocampus and neocortex: insights from the successes and failures of connectionist models of learning and memory. Psychol Rev 3:419-457.

Moscovitch M, Nadel L, Winocur G, Gilboa A, Rosenbaum RS (2006) The cognitive neuroscience of remote episodic, semantic and spatial memory. Curr Opin Neurobiol 16:179-190.

Nadel L, Samsonovich A, Ryan L, Moscovitch M (2000) Multiple trace theory of human memory: computational, neuroimaging, and neuropsychological results. Hippocampus 10:352-368.

Raz N, Lindenberger U, Rodrigue KM, Kennedy KM, Head D, Williamson A, Dahle C, Gerstorf D, Acker JD (2005) Regional brain changes in aging healthy adults: general trends, individual differences and modifiers. Cereb Cortex 15:1676-1689.

Reed JM, Squire LR (1998) Retrograde amnesia for facts and events: findings from four new cases. J Neurosci 18:3943-3954. 
Rempel-Clower N, Zola SM, Squire LR, Amaral DG (1996) Three cases of enduring memory impairment following bilateral damage limited to the hippocampal formation. J Neurosci 16:5233-5255.

Rey A (1964) L'Exaen clinique psychologie [The clinical exam in psychology]. Paris: Presses Universitaires de France.

Ribot T (1881) Les Maladies de la Memoire [Diseases of memory]. New York: Appleton-Century-Crofts.

Rosenbaum RS, McKinnon MC, Levine B, Moscovitch M (2004) Visual imagery deficits, impaired strategic retrieval, or memory loss: disentangling the nature of an amnesic person's autobiographical memory deficit. Neuropsychologia 42:1619-1635.

Rosenbaum RS, Kohler S, Schacter DL, Moscovitch M, Westmacott R, Black SE, Gao F, Tulving E (2005) The case of K.C.: contributions of a memoryimpaired person to memory theory. Neuropsychologia 43:989-1021.

Sagar HJ, Cohen NJ, Corkin S, Growdon JH (1985) Dissociations among processes in remote memory. Ann NY Acad Sci 444:533-535.

Salat DH, van der Kouwe AJW, Tuch DS, Quinn BT, Fischl B, Dale AM, Corkin S (2006) Neuroimaging H.M.: a 10-year follow-up examination. Hippocampus 16:936-945.

Sanders HI, Warrington EK (1971) Memory for remote events in amnesic patients. Brain 94:661-668.

Schmolck H, Kensinger E, Corkin S, Squire LR (2002) Semantic knowledge in patient H.M. and other patients with bilateral medial and lateral temporal lobe lesions. Hippocampus 12:520-533.

Shimamura AP, Squire LR (1986) Korsakoffs syndrome: a study of the relation between anterograde amnesia and remote memory impairment. Behav Neurosci 100:165-170.

Shrager Y, Gold JJ, Hopkins RO, Squire LR (2006) Intact visual perception in memory-impaired patients with medial temporal lobe lesions. J Neurosci 26:2235-2240.
Squire LR (1974) Remote memory as affected by aging. Neuropsychologia 12:429-435.

Squire LR, Alvarez P (1995) Retrograde amnesia and memory consolidation: a neurobiological perspective. Curr Opin Neurobiol 5:169-177.

Squire LR, Bayley PJ (2006) The neuroanatomy of very remote memory. Lancet Neurol 5:112-113.

Squire LR, Clark RE, Bayley PJ (2004a) Medial temporal lobe function and memory. In: The cognitive neurosciences, Ed 3 (Gazzinaga M, ed), pp 691-708. Cambridge, MA: MIT.

Squire LR, Stark CE, Clark RE (2004b) The medial temporal lobe. Annu Rev Neurosci 27:279-306.

Steinvorth S, Levine B, Corkin S (2005) Medial temporal lobe structures are needed to re-experience remote autobiographical memories: evidence from H.M. and W.R. Neuropsychologia 43:479-496.

Vincent A, Buckley C, Schott JM, Baker I, Dewar BK, Detert N, Clover L, Parkinson A, Bien CG, Omer S, Lang B, Rossor MN, Palace J (2004) Potassium channel antibody-associated encephalopathy: a potentially immunotherapyresponsive form of limbic encephalitis. Brain 127:701-712.

Wais PE, Wixted JT, Hopkins RO, Squire LR (2006) The hippocampus supports both the recollection and the familiarity components of recognition memory. Neuron 49:459-466.

Warrington EK (1996) Studies of retrograde memory: a long-term view. Proc Natl Acad Sci USA 93:13523-13526.

Warrington EK, Duchen LW (1992) A re-appraisal of a case of persistent global amnesia following right temporal lobectomy: a clinicopathological study. Neuropsychologia 30:437-450.

Warrington EK, Silberstein M (1970) A questionnaire technique for investigating very long term memory. Q J Exp Psychol 22:508-512.

Wechsler D (1981) Wechsler adult intelligence scale-revised. London, New York: Psychological Corporation. 